\title{
Una bioética en clave latinoamericana: apor- tes de la Declaración Universal sobre Bioética y Derechos Humanos de UnESCO
}

\author{
PAULA SIVERINO BAVIO*
}

\begin{abstract}
SUMARIO: I. INTRODUCCIÓN.- II. CONCEPTOS PREVIOS: LA DEFINICIÓN DE BIOÉTICA Y EL ENFOQUE PRINCIPIALISTA.- III. BIOÉTICA Y DERECHOS HUMANOS.-IV. LA DECLARACIÓN UNIVERSAL SOBRE BIOÉTICA Y DERECHOS HUMANOS.- V. COLOFÓN.
\end{abstract}

\section{INTRODUCCIÓN}

La bioética es una disciplina joven, considerada parte de la ética normativa, pero cuya vocación interdisciplinaria ha propiciado un fértil campo de estudio en diversas áreas científicas y sociales, unidas por el interés en la reflexión sobre el presente y futuro de la humanidad. Nacida formalmente en los años setenta en el contexto de la preocupación por la regulación ética de las investigaciones sobre seres humanos, hoy, al menos en Europa y América Latina, es considerada una disciplina esencial para la supervivencia humana, en tanto se ocupa de las relaciones entre ética, tecnología, sociedad, equidad y desarrollo, teniendo en vista que no todo lo técnicamente posible es éticamente recomendable.

A continuación, reseñaremos muy sintéticamente la definición de bioética, sus raíces históricas y las principales características del principialismo, enfoque predominante en la visión de la disciplina hasta el inicio del siglo XXI, para luego adentrarnos en la propuesta de la bioética de los derechos humanos y el estudio de la Declaración Universal de Bioética y Derechos Humanos.

\section{CONCEPTOS PREVIOS: LA DEFINICIÓN DE BIOÉTICA Y EL ENFOQUE PRINCIPIALISTA}

En la primera edición de la Enciclopedia de bioética editada por Warren Reich (1978), se define bioética como «el estudio sistemático de la conducta humana en el área de las ciencias de la vida y la atención de la salud, en tanto que dicha conducta es examinada a la luz de los principios y valores morales». 
En su segunda edición (1995), leemos:

[...] Bioética es una palabra compuesta derivada del griego bios (vida) y ethiké (ética). Puede ser definido como el estudio sistemático de las decisiones morales -incluyendo visiones, decisiones conductas y políticas morales - de las ciencias de la vida y la atención a la salud, empleando una variedad de metodologías éticas en un contexto ético. Las dimensiones morales que se examinan en la bioética están evolucionando constantemente, pero tienden a focalizarse en algunas cuestiones mayores: iQué es o debe ser la visión moral de uno (o de la sociedad)? ¿Qué clase de persona debería ser uno (o debería ser la sociedad)? ¿Qué debe hacerse en situaciones específicas?:Cómo nos encontramos armoniosamente $?^{1}$

La bioética, integrada por las voces bios, del griego 'vida humana', y ethiké , denota así no solo un campo particular de investigación, la intersección de la ética y las ciencias de la vida, sino también una disciplina académica, una fuerza política en los estudios de medicina, biología y medio ambiente, y una perspectiva cultural ${ }^{3}$. Expresa, de alguna manera, el dilema moderno entre la libertad individual y la responsabilidad social. Se caracteriza por ser un campo en formación, de abordaje interdisciplinario, eminentemente práctico.

Hoy se acepta que la bioética nace de una triple raíz:

- la defensa de los derechos humanos en la postguerra mundial y el movimiento por los derechos civiles en los Estados Unidos, ambos en su relación con la medicina y la salud;

- el poderío y la ambigüedad moral del poderío del desarrollo científico tecnológico para la supervivencia de la especie humana y el bienestar de las personas;

- los problemas de justicia en los sistemas de salud ${ }^{4}$.

La rama de la disciplina llamada bioética teórica estudia los problemas relativos a los fundamentos de la disciplina, básicamente cuestiones de orden teórico — cuál o cuáles teorías éticas ofrecen mejores elementos para resolver los dilemas que se presenten-y metodológico — encontrar o desarrollar la metodología para enfrentar los nuevos problemas morales-.

1 TEALDI, Juan Carlos. «Teoría tradicional». En Juan Carlos Tealdi (director). Diccionario latinoamericano de bioética. Bogotá: UnEsco, Universidad Nacional de Colombia, 2008, p.127.

2 Mainetti, José A. Antropo-bioética. La Plata: Quirón Editora, 1995. p.13.

3 Callahan, Daniel. «Bioethics». En Warren Reich (editor). Encyclopaedia of Bioethics. Vol. 1. Nueva York: Simon \& Schuster Macmillan, 1995, pp. 247-258.

4 TEALDI, Juan Carlos. Bioética de los derechos humanos. Investigaciones médicas y dignidad humana. México D.F.: UnAM, 2008, p. 52. 
Respecto de las cuestiones metodológicas, el método de los principios, nacido al calor del «Informe Belmont $»^{5}$ y reformulado por Beauchamp y Childress ${ }^{6}$, devino como el más popular y extendido al analizar los dilemas surgidos de la práctica clínica. Es un modelo deductivo, que parte de la base de la moralidad común y la tradición médica, según las cuales principios no absolutos forman el nivel general de enunciados normativos, los que deben ser en cada caso interpretados, balanceados y especificados conforme con el modelo de coherencia. Estos son los principios de autonomía, beneficencia, no maleficencia y justicia.

Tal como advierte Tealdi, este ascenso progresivo de la razón en búsqueda de niveles de justificación conllevó pasar del carácter «básico» que se pedía a los principios originalmente enunciados a un carácter «fundamental», y se sostenía que existen principios éticos fundamentales aceptados por todas las épocas y culturas, y aplicables, por lo tanto, a todos los agentes y acciones en todo tiempo y lugar; este «fundamentalismo moral» fue fuertemente criticado ${ }^{7}$, si bien vale aclarar que no todo principialismo conlleva un fundamentalismo moral.

Hay, sin embargo, diversas alternativas metodológicas al principialismo anglosajón, tales como el casuismo, la teoría de la virtud, la ética feminista y la hermenéutica ${ }^{8}$, y el enfoque que entiende como indisoluble la relación entre bioética y derechos humanos.

El principialismo ha sido objetado: el rol asignado a los principios como meros nombres vacíos sin sustancia moral o poder de guía; ofrecer una posición sumamente confusa; la incompatibilidad entre deontología y utilitarismo en su propuesta; el carecer de una teoría general; y no fijar un sistema para dirimir los conflictos entre principios?

Pero sin duda una de las críticas más fuertes proviene del enfoque latinoamericano de bioética y derechos humanos, al denunciar que «la conversión de la idea de justicia en un principio prima facie y la desvinculación entre derecho legal y derecho moral, conduce en el principialismo a la disolución de la salud como derecho humano básico» ${ }^{10}$, al subordinar los derechos humanos a los principios éticos, con lo cual se cuestiona el carácter absoluto e inalienable de estos y el rol gravitante del concepto de dignidad humana.

Como veremos, la preocupación por la defensa de la dignidad humana y los derechos fundamentales en relación con la bioética ha sido recogida por la comunidad internacional y plasmada en un importante

5 The National Comission for the Protection of Human Subjects in Biomedical and Behavoral Reaserch (19741978). The Belmont Report DHWE, Washington, 1978.

6 Beauchamp, Tom y James Childress. Principles of Biomedical Ethics. Cuarta edición. Nueva York: Oxford University Press, 1994.

7 TEALDI, Juan Carlos. Los principios de Georgetown: Análisis crítico. En V. Garrafa, M. Kottow, A. Saada (editores). Estatuto epistemológico de la Bioética. México D.F.: UNAM-UNESCO, 2005, p. 37.

8 MAINETTI, José. A. Op. cit., p. 33.

9 Clouser, K.D. y B. Gert. «A Critic of Principalism». Journal on Medicine and Philosophy 15: 219-236, 1990.

10 TeALDI, Juan Carlos. Op. cit., p. 43. 
documento de UnEsco: la Declaración Universal de Bioética y Derechos Humanos.

\section{BIOÉTICA Y DERECHOS HUMANOS}

Reconociendo como base a la Declaración Universal de los Derechos Humanos (1948), fortalecida luego por la Declaración de Helsinki (1964) y los pactos internacionales de Derechos Civiles y Políticos (1966), y de Derechos Económicos Sociales y Culturales, encontramos una serie de documentos internacionales que abonaron el camino hacia la Declaración Universal sobre Bioética y Derechos Humanos.

Así, en entre los instrumentos que contienen un explícita asociación entre bioética y derechos humanos, podemos señalar la Declaración Universal sobre el Genoma Humano y los Derechos Humanos (1997) y las Orientaciones para su Aplicación (1999); el Convenio para la Protección de los Derechos Humanos y la Dignidad del Ser Humano con Respecto a las Aplicaciones de la Biología y la Medicina (Convenio de Oviedo, 1997); la Declaración Universal sobre Datos Genéticos Humanos (2003); y finalmente la Declaración Universal sobre Bioética y Derechos Humanos (2005).

El origen de la bioética ha sido situado por los historiadores de la disciplina en la reformulación de la ética de la investigación médica por los juicios de los médicos nazis que fueron seguidos por el Código de Nuremberg, en 1947. Seguimos a Tealdi cuando señala que en 1997 una denuncia sobre investigaciones no éticas para reducir la transmisión perinatal del virus del SIDA marcó el final del consenso que se había entendido como sustrato común de toda bioética, a pesar de sus distintos enfoques.

Ese sustrato había sido la relación entre la ética y los derechos humanos que, como se señalaba, quedara establecida después de 1948 con la Declaración Universal de Derechos Humanos como expresión mayor y con el Código de Nuremberg que la había precedido como referencia específica en el campo de la investigación médica ${ }^{11}$, entendida no solo como un documento internacional para los médicos sino también como expresión de continuidad de la moral universalista de los derechos humanos.

Paralelamente a la denuncia mencionada, a fines de los años noventa, algunos bioeticistas, esencialmente representantes (o adherentes) del principialismo angloamericano, reclamaron una revisión de la Declaración de Helsinki; postulaban la introducción de un doble estándar - un tratamiento para los pacientes de los países desarrollados y otro para los países emergentes o subdesarrollados_-, medida tendente a restarle rigurosidad al sistema internacional de revisión ética de las 
investigaciones biomédicas, fundamentalmente en torno a dos puntos álgidos, tales como la flexibilización del uso de placebos y el abandono de la garantía de acceso al mejor tratamiento probado tanto al ingreso como a la salida de los sujeto de investigación en un estudio ${ }^{12}$.

Esto generó, en los ámbitos de discusión internacional, una fuerte reacción de calificados representantes de la bioética latinoamericana, particularmente de Brasil y Argentina, que fundaron su rechazo a las modificaciones de los instrumentos internacionales mencionados en la defensa de un único estándar mínimo, basado en la tutela de los derechos humanos de los participantes en investigaciones biomédicas ${ }^{13}$. La postulación de una bioética de los derechos humanos fue realizada por primera vez en octubre de 2001, en Buenos Aires, como apertura del Encuentro Nacional de Bioética y Derechos Humanos.

La bioética de los derechos humanos se desarrolló entonces a partir de dos tesis básicas: la primera de ellas, tesis histórico- sociológica, consiste en que si bien la bioética es un campo de reflexión ético-normativo, aún admitiendo diferentes métodos de aproximación, debe reconocer como mínimo indiscutible el respeto a la moral universal de los derechos humanos. La segunda, tesis filosófico-normativa, sostiene que «toda concepción teórica de la bioética debe dar cuenta del lugar que ocupa la moral del sentido común, los valores, los principios y las virtudes en la dimensión ética de la teoría, pero a la vez debe fundamentar las relaciones que la racionalidad moral tiene con otras racionalidades, como la jurídica, la científica, la tecnológica y la estética, en el conjunto del campo normativo denominado bioética» ${ }^{14}$.

Esta posición, que concibe a la bioética como una bioética de los derechos humanos, sostiene como postulados básicos:

- una indisoluble asociación entre la bioética y los derechos humanos;

- una concepción de la bioética en la cual esta se ocupa no solo de los problemas éticos originados en el desarrollo científico y tecnológico, sino también de las condiciones relativas a un medio ambiente ecológicamente equilibrado en la diversidad natural, y de todos los problemas éticos relativos a la atención y el cuidado de la vida y de la salud, desde una perspectiva de salud integral entendida como el desarrollo de las capacidades humanas esenciales para hacer viables una vida saludable para todos;

- la idea de justicia como fundamento esencial que debe entenderse recurriendo al contexto interpretativo de los derechos humanos; 
- la universabilidad de una bioética de los derechos humanos basada en el concepto de la dignidad humana; y

- la necesidad de construir una bioética latinoamericana; reconocida la necesidad de considerar el ethos donde surgen las construcciones morales de cada comunidad, es indudable que América Latina es una comunidad con suficientes atributos de identidad para ser pensada como un ethos propio, y se trata de una tarea imprescindible al construir una bioética de los derechos humanos en América Latina.

Es preciso aclarar que el universalismo de una bioética cuyos principios especifiquen los contenidos mínimos de la moral básica común de los derechos humanos es compatible con el respeto de la diversidad cultural y el pluralismo. El universalismo moral supone un sistema de principios éticos que se impone a todas las personas, y que asigna a todos los mismos beneficios y las mismas cargas, de modo tal que no se perjudique ni se privilegie de modo arbitrario a ninguna persona o grupo determinado ${ }^{15}$.

El Convenio de Oviedo supone un claro ejemplo de lo dicho. Este, sin desconocer el pluralismo de valores, no renuncia a la necesidad de establecer entre estos una jerarquía de carácter objetivo: en el preámbulo y en sus considerandos, así como en su artículo primero, elige el respeto de la dignidad de la persona como valor último y canon de interpretación de todas las otras disposiciones. De ese modo, hace perpetuo un principio común a las tradiciones constitucionales europeas, ya sea que este se encuentre expreso o solamente implícito en las respectivas cartas constitucionales $^{16}$.

Espacio de la llamada «bioética latina» o «mediterránea», en Europa continental el desarrollo de la disciplina ha mantenido en términos generales una estrecha relación entre bioética y derechos humanos. Prueba de esto son el Convenio para la Protección de los Derechos Humanos y la Dignidad del Ser Humano con respecto a las Aplicaciones de la Biología y la Medicina - también llamada Convención Europea de Bioética o Convenio de Oviedo-, y la Carta de los Derechos Fundamentales de la Unión Europea, la cual declara solemnemente fundarse «sobre los valores indivisibles y universales de la dignidad humana, la libertad, la igualdad y la solidaridad». Mientras que en la concepción norteamericana no se considera a la salud como un derecho humano básico y se utiliza la distinción entre «derecho legal» $\mathrm{y}$ «derecho moral», distinción de fundamento estrictamente nacional, es muy distinto el escenario europeo, con sistemas sanitarios que incluyen seguros nacionales de salud y garantías de protección de la salud como derecho humano ${ }^{17}$. 


\section{LA DECLARACIÓN UNIVERSAL SOBRE BIOÉTICA Y DERECHOS HUMANOS}

Conforme se señalara, a fines de 2004 comenzaron los trabajos preparatorios para una Declaración Universal de Bioética. Un hito importante lo constituyó la Carta de Buenos Aires sobre Bioética y Derechos Humanos, documento producido al final de un seminario regional convocado en Buenos Aires por el gobierno argentino y la UNESCO, en noviembre de 2004, que habría de tener, junto con las conclusiones del seminario regional, un notorio impacto sobre el texto que la UNESCO venía preparando. ${ }^{18}$ Luego del estudio y discusión de varios borradores de anteproyectos, en octubre de 2005 la UNESCO aprobó la Declaración Universal sobre Bioética y Derechos Humanos; fue la primera vez en la historia de la bioética que los Estados miembros se comprometían, y comprometían con ello a la comunidad internacional, a respetar y aplicar los principios fundamentales de la bioética reunidos en un texto único ${ }^{19}$.

Así, se sostuvo que:

$\mathrm{Al}$ abordar los problemas éticos que plantea la medicina, las ciencias de la vida y las tecnologías conexas en sus vertientes relacionadas con el ser humano, la Declaración, como se infiere de su mismo título, fundamenta en ella los principios consagrados en las normas que rigen el respeto por la dignidad de la persona, los derechos humanos y las libertades fundamentales. Por el hecho de inscribir la bioética en los derechos humanos internacionales y garantizar el respeto por la vida de las personas, la Declaración reconoce la interrelación existente entre la ética y los derechos humanos en el terreno concreto de la bioética ${ }^{20}$.

En el preámbulo de la declaración, se explicita el ser conscientes de la «excepcional capacidad que posee el ser humano para reflexionar sobre su existencia y su entorno, así como para percibir la injusticia, evitar el peligro, asumir responsabilidades, buscar la cooperación [...]», teniendo en cuenta que los adelantos de la ciencia y la tecnología afectan cada vez más la concepción de la vida y la vida misma, y que ello trae consigo una demanda por una respuesta universal o los problemas éticos que se suscitan, lo cuales deben examinarse al considerar el respeto por la dignidad humana, los derechos humanos y las libertades fundamentales. Se resuelve, por lo tanto, que es necesario y conveniente que la comunidad internacional establezca principios universales que sirvan de fundamento a la humanidad para dar respuesta a estas controversias.

A continuación, el preámbulo menciona una larga lista de instrumentos del Derecho internacional de los derechos humanos y otros instrumentos

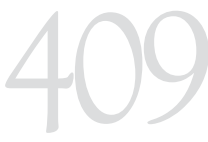

UNA BIOÉTICA EN CLAVE LATINOAMERICANA: APORTES DE LA DECLARACIÓN UNIVERSAL SOBRE BIOÉTICA Y DERECHOS HUMANOS DE UNESCO

18 lbid., p. 295.

19 Para un relato completo de los antecedentes de la declaración con especial mención del trabajo de los expertos latinoamericanos, véase el capítulo IV de la ya citada obra de Tealdi: Bioética de los derechos humanos...

20 Matsuura, Koichiro. «Prefacio a la Declaración Universal sobre Bioética y Derechos Humanos». UnEsco, 2005. En <http://unesdoc.unesco.org/images/0014/001461/146180S.pdf>. Fecha de consulta: 7 de febrero de 2009 . 
internacionales, tales como el Acuerdo de los Derechos Intelectuales Vinculados con el Comercio (ADPIC), la declaración de Doha relativa a los ADPIC y salud pública, y demás instrumentos internacionales de Naciones Unidas y sus organismos especializados, particularmente la Organización de las Naciones Unidas para la Agricultura y la Alimentación (FAO) y la Organización Mundial de la Salud (OMS). Entre los instrumentos internacionales y regionales propios de la bioética, menciona la Convención para la Protección de los Derechos Humanos y la Dignidad Humana con respecto a la Aplicación de la Medicina y la Biología (Convención sobre los Derechos Humanos y la Biomedicina del Consejo de Europa, junto con sus protocolos adicionales); los códigos de conducta, las directrices internacionales y regionales sobre bioética, como la Declaración de Helsinki de la Asociación Médica Mundial, aprobada en 1964 y enmendada sucesivamente en 1975, 1983, 1989, 1996 y 2000; así como las guías éticas internacionales para investigación biomédica que involucra a seres humanos del Consejo de Organizaciones Internacionales de las Ciencias Médicas, aprobadas en 1982 y enmendadas en 1993 y 2002.

Luego, en las consideraciones, se resalta el rol de la UNESCO en la definición de principios universales, los cuales se vuelven necesarios ya que las cuestiones de bioética, que tienen forzosamente una dimensión internacional, se deben tratar como un todo, teniendo en cuenta no solo el desarrollo científico actual sino también su evolución futura. En el preámbulo, se reconoce que el desarrollo de la ciencia puede aportar grandes beneficios a la humanidad, siempre que se respeten la dignidad humana, los derechos humanos y las libertades fundamentales. Se reconoce que la salud no depende únicamente de los progresos de la investigación científica y tecnológica, sino también de factores psicosociales y culturales; que las decisiones relativas a las cuestiones éticas relacionadas con la medicina, las ciencias de la vida y tecnologías conexas pueden tener repercusiones no solo en los individuos o grupos sino en la especie humana en su conjunto; y que prueba de ellos son las repercusiones negativas que la conducta científica y tecnológica poco ética ha tenido en comunidades indígenas y locales.

Se reconoce la necesidad de que la sensibilidad moral y la reflexión ética sean partes integrantes del proceso de desarrollo tecnológico y científico, y es conveniente elaborar nuevos enfoques de responsabilidad social y, en este sentido, prestar atención a la situación de la mujer, así como en cuestión de cooperación internacional considerar las necesidades específicas de los países en desarrollo, comunidades indígenas y las poblaciones vulnerables.

La declaración trata acerca de las cuestiones éticas relacionadas con la medicina, las ciencias de la vida y las tecnologías conexas aplicadas a los seres humanos; considera sus dimensiones sociales, jurídicas y ambientales, y va dirigida a los Estados. Imparte orientación, cuando procede, 
para las decisiones o prácticas de individuos, grupos, comunidades, instituciones y empresas, públicas o privadas (artículo 1, incisos 1 y 2).

Subyace a estas consideraciones el entender que la bioética se ocupa no solo de los problemas éticos originados en el desarrollo científico y tecnológico, sino también de las condiciones relativas a un medio ambiente ecológicamente equilibrado en la diversidad natural y de todos los problemas éticos relativos a la atención y el cuidado de la vida y de la salud, desde una perspectiva de salud integral, entendida como el desarrollo de las capacidades humanas esenciales para hacer viables una vida saludable para todos ${ }^{21}$.

En su artículo segundo, la declaración enuncia sus objetivos, entre ellos:

a) proporcionar un marco universal de principios y procedimientos que sirvan como guía a los Estados en la formulación de legislaciones, políticas, etcétera, en el ámbito de la bioética;

b) orientar la acción de grupos, individuos, comunidades, instituciones y empresas públicas y privadas;

c) promover el respeto por la dignidad humana y promover los derechos humanos, al velar por el respeto de la vida de los seres humanos y las libertades fundamentales;

d) reconocer la importancia de la investigación científica y las repercusiones beneficiosas del desarrollo científico y tecnológico, y destacar así la necesidad de que esta se realice en el marco de los principios éticos de la declaración y de que respete la dignidad humana, los derechos humanos y las libertades fundamentales;

e) fomentar un diálogo interdisciplinario y pluralista sobre las cuestiones bioéticas;

f) promover un acceso equitativo a los adelantos de la medicina, la ciencia y la tecnología, así como la circulación y el aprovechamiento compartido relativo a esos adelantos y sus respectivos beneficios, y prestar especial atención a las necesidades de los países en vías de desarrollo;

g) salvaguardar y proteger los intereses de las generaciones presentes y venideras; $y$,

h) destacar la importancia de la biodiversidad y su conservación como preocupación común de la especie humana.

A partir del artículo tercero y hasta el artículo decimoséptimo, la declaración enuncia sus principios. Vale destacar que, en primer lugar, encontramos el pleno respeto de la dignidad humana, los derechos humanos y las libertades fundamentales; los intereses y el bienestar de la persona

UNA BIOÉTICA EN

CLAVE LATINO-

AMERICANA:

APORTES DE LA

DECLARACIÓN

UNIVERSAL

SOBRE BIOÉTICA

Y DERECHOS

HUMANOS DE

UNESCO 
deberán tener prioridad con respecto al interés exclusivo de la ciencia o de la sociedad (artículo 3, incisos 1 y 2).

Los principios aquí presentes son los que siguen:

1. Respeto por la dignidad humana, los derechos humanos y las libertades fundamentales (artículo 3, inciso 1).

2. Preeminencia del interés y bienestar de la persona humana por sobre el de la ciencia o la sociedad (artículo 3, inciso 2).

3. Potencialización de beneficios y minimización de efectos nocivos en el fomento de la investigación, la aplicación de las prácticas médicas y tecnologías conexas particularmente respecto de los participantes en investigación en seres humanos (artículo 4).

4. Respeto por la autonomía individual y protección de las personas carentes de la posibilidad de ejercer su autonomía (artículo 5).

5. Consentimiento libre, informado y revocable, previo a toda intervención médica preventiva, diagnóstica o terapéutica, o a la participación en investigaciones científicas; las excepciones a esta regla solo tendrán cabida siempre que sean conformes con normas éticas y jurídicas de los Estados compatibles con la declaración; en investigaciones en comunidades o grupos de personas puede recabarse un consentimiento grupal que no sustituye ni invalida el consentimiento del individuo (artículo 6 , incisos 1,2 y 3 ).

6. Especial protección a personas con capacidad disminuida para tomar decisiones: participar en las decisiones en la medida de sus posibilidades; no formar parte de investigaciones salvo que redunden en su beneficio directo, etcétera (artículo 7).

7. Respeto frente a la vulnerabilidad humana y protección de la integridad personal; protección especial de grupos vulnerables (artículo 8).

8. Respeto por la privacidad de las personas y la confidencialidad de la información (artículo 9).

9. Respeto por la igualdad fundamental de los seres humanos en derechos y dignidad, de modo tal que sean tratados con justicia y equidad (artículo 10).

10. Prohibición de discriminación o estigmatización (artículo 11).

11. Respeto de la diversidad cultural y el pluralismo (artículo 12).

12. Fomento de la solidaridad y de la cooperación internacional (artículo 13).

13. Promoción de la salud y responsabilidad social. En el acceso a la salud, se comprenden el acceso a medicamentos y atención médica de calidad, agua y alimentación adecuada, la superación de la exclusión, y la reducción de la pobreza y del analfabetismo (artículo 14). 
14. Aprovechamiento compartido de los beneficios que surjan de la investigación científica, en particular en los países en desarrollo (artículo 15).

15. Protección de las generaciones futuras (artículo 16).

16. Protección del medio ambiente, la biosfera y la diversidad (artículo 17).

En el acápite dedicado a la aplicación de los principios de la declaración, se contemplan cuatro esferas de acción: adopción de decisiones y tratamiento de las cuestiones bioéticas (artículo 18); comités de ética (artículo 19); evaluación y gestión de riesgos (artículo 20); y prácticas transnacionales (artículo 21).

Respecto de la adopción de decisiones y tratamientos de las cuestiones bioéticas, se fomentarán la integridad, la honestidad, el profesionalismo y la transparencia, y se procurará utilizar los mejores conocimientos y métodos científicos disponibles; además de entablar un diálogo permanente entre las personas, los profesionales involucrados y la sociedad, y de promover un debate público, pluralista e informado.

Otro punto importante es el mencionado en el artículo 21, referido a las prácticas transnacionales, particularmente en el inciso 2 , en el que se refiere que, cuando una investigación se realice o se lleve a cabo de cualquier otra manera en un Estado o en varios Estados y sea financiada por una fuente ubicada en un tercer Estado, la actividad debería someterse a un nivel apropiado de examen ético en el Estado anfitrión o los Estados anfitriones, así como en el Estado donde está ubicada la fuente de financiación. Ese examen deberá basarse en normas éticas y jurídicas que sean compatibles con la declaración.

El artículo continúa diciendo que las actividades transnacionales en salud deberían responder a las necesidades de los países anfitriones; se deberá la importancia de que la investigación científica contribuya a paliar los problemas urgentes de salud a nivel mundial. Asimismo, al negociar un acuerdo de investigación, se deberían establecer condiciones de colaboración y un acuerdo de beneficios con una participación equitativa de las partes que intervienen. Por último, se entiende que los Estados deberían tomar medidas adecuadas en el plano nacional e internacional para luchar contra el bioterrorismo, el tráfico ilícito de órganos, tejidos, muestras, recursos genéticos y materiales relacionados con la genética.

Dentro de las tareas de promoción de la declaración, se manifiesta que los Estados deberían adoptar todas las disposiciones adecuadas, tanto de carácter legislativo como de otra índole, para poner en práctica los principios de la declaración, así como alentar la creación de comités de ética pluralistas, independientes y pluridisciplinarios (artículo 22). El artículo 23 recoge la necesidad de fomentar la educación y la formación relativas a la bioética en todos los planos. El artículo 24 explica la

UNA BIOÉTICA EN

CLAVE LATINO-

AMERICANA:

APORTES DE LA

DECLARACIÓN

UNIVERSAL

SOBRE BIOÉTICA

Y DERECHOS

HUMANOS DE

UNESCO 
necesidad de fomentar la cooperación internacional en cuanto a la libre circulación y aprovechamiento del conocimiento científico, en tanto que el artículo 25 refiere al seguimiento de la declaración, que estará a cargo de la UNESCO.

De gran trascendencia son los últimos tres artículos de la declaración. El artículo 26 establece que la declaración debe entenderse como un todo y que sus principios son complementarios e interdependientes. Seguidamente, el artículo 27 menciona las pautas de limitación a los principios: la limitación debe hacerse por ley —en particular leyes para investigar y sancionar delitos, defender la salud pública y los derechos humanos y libertades fundamentales-, y dicha ley debe ser compatible con el Derecho internacional de los derechos humanos. Concluye el articulado que ninguna disposición de la declaración podrá interpretarse como si se concediera a algún Estado, grupo o individuo derecho alguno a emprender actividades o realizar actos que vayan contra los derechos humanos, las libertades fundamentales o la dignidad humana.

\section{COLOFÓN}

En el Perú, la bioética es una disciplina joven, que paulatinamente comienza a trascender más allá de la esfera del manejo específico de los problemas relacionados con la práctica clínica en los ámbitos del cuidado de la salud para, tomando como base la reflexión ética y las respuestas normativas el marco propuesto por los derechos humanos, instalarse como un espacio de reflexión plural e interdisciplinario de los dilemas suscitados por el impacto de las tecnologías en la sociedad, particularmente sobre los grupos más vulnerables.

En este sentido, coincidimos en que la Declaración Universal sobre Bioética y Derechos Humanos ha marcado un significativo progreso para la historia de la bioética, en vista de que:

a) de ella emana autoridad, en tanto producto de un organismo de las Naciones Unidas;

b) el universalismo de su contenido asocia el conjunto de principios éticos que declara con el Derecho internacional de los derechos humanos;

c) el alcance de su aplicación se dirige a los Estados nacionales ${ }^{22}$.

Existen, sin duda, muy interesantes temas que debieran ser objeto de debate en este campo, y otros que precisan una urgente reflexión y respuesta normativa. La bioética tiene mucho que aportar al Derecho y, como dice un poeta, «se hace camino al andar». 